\title{
Degradation of the Reactive Blue 4 Dye in Aqueous Solution Using Zero-Valent Copper Nanoparticles
}

\author{
Cristiana Resende Marcelo, Gustavo Alves Puiatti, Mayra Aparecida Nascimento, \\ André F. Oliveira, and Renata P. Lopes \\ Department of Chemistry, Federal University of Viçosa, 36570-000 Viçosa, MG, Brazil \\ Correspondence should be addressed to Renata P. Lopes; renata.plopes@ufv.br
}

Received 5 June 2017; Accepted 25 September 2017; Published 12 February 2018

Academic Editor: Sherine Obare

Copyright (c) 2018 Cristiana Resende Marcelo et al. This is an open access article distributed under the Creative Commons Attribution License, which permits unrestricted use, distribution, and reproduction in any medium, provided the original work is properly cited.

\begin{abstract}
The degradation of the Reactive Blue 4 (RB4) dye by zero-valent copper nanoparticles (nZVC) was investigated. Degradation rates of approximately $90 \%$ were reached within 10 minutes of reaction. Total Organic Carbon (TOC) analysis shows that the dye molecules undergo mineralization, therefore indicating the degradation process is oxidative. Experimental tests, held in the presence of tertiary butyl alcohol, acting as a hydroxyl radicals $(\bullet \mathrm{OH})$ captor, and copper (I) oxide, demonstrated that the reaction mechanism is governed by the concentration of $\mathrm{Cu}(\mathrm{I})$ instead of $\bullet \mathrm{OH}$. The second-order kinetics model was the most appropriate one to explain the experimental data. Higher values of the reaction rate constant were obtained in higher temperatures and higher nZVC doses and in lower RB4 initial concentrations. The initial pH in more acidic conditions ( 3 and 4) was kinetically more favorable to the degradation reaction; the activation energy was estimated to be $42 \mathrm{~kJ} \mathrm{~mol}^{-1}$ based on calculations using the experimental data. Finally, the recovered nanoparticles were utilized on a new reaction cycle, showing a small loss of their efficiency and catalytic activity.
\end{abstract}

\section{Introduction}

The textile and clothing industrial sector has a significant participation on the global economy and a great capacity of creating jobs $[1,2]$. The textile and clothing industries generate effluents with high loads of organic compounds pollutants, especially dyes, which are the main inputs of the productive process [3]. The release of dyes on water bodies can cause harm to the environment and human health [3-6]; therefore, the disposal of effluents containing these compounds requires a prior adequate treatment process. Due to chemical, environmental, and toxicological aspects, many researchers have been looking for more attractive and efficient ways to treat effluents from the textile industry. These studies mainly involve adsorption [7-10], electrochemical [11-13], photodegradation [14-19], and bioremediation [20-22] processes.
The uses of zero-valent bimetallic particles in the form of powder, granular, or metallic cubes [23], and even in nanometric scale $[24,25]$, are examples of alternative approaches for the treatment of these effluents. Nanometricsized metallic particles have advantages compared to microsized particles, including higher specific superficial areas, superficial energies and active site densities [26-28]. The primary focus on metallic nanoparticles in degradation studies is based on zero-valent iron (nZVI), because of several desirable attributes such as high activity, low cost, easy obtainment of the starting material, and low toxicity [25-27]. However, zero-valent iron nanoparticles have the disadvantages of being readily oxidized and reactive only in acidic conditions, requiring rigorous $\mathrm{pH}$ control during the reaction $[27,29]$.

Other materials have been used as alternatives to iron, such as copper [28]. Although the studies with zero-valent copper nanoparticles (nZVC) are still scarce, the use of 
this material is highly attractive in degradation processes of organic compounds [30-32]. The redox potential of copper $\left(E_{0}=+0.34 \mathrm{~V}\right)$ is higher than iron's $\left(E_{0}=-0.44 \mathrm{~V}\right)$; copper acts as a good electron donor in solution and, therefore, participates in organic pollutants degradation by electrochemical reactions $[32,33]$.

The use of copper nanoparticles on organic pollutants degradation processes have shown to be effective [31-34]. Studies demonstrate that metallic nanoparticles are capable of promoting the degradation of dyes, which occurs by reductive $[35,36]$ or oxidative processes $[34,37]$. During reductive processes, the oxidized metal supplies electrons to the dye reduction. In the case of anthraquinone, the reductive process may result in the breakage of the ring bond and, promote color removal in the solution. In addition, the breakage of the amine group $\mathrm{C}-\mathrm{N}$ bond attached to the molecule central benzene ring can occur, which generates primary amines as a product [35]. During an oxidative process, as long as it occurs under oxic conditions, zero-valent copper nanoparticles can favor the in situ hydrogen peroxide $\left(\mathrm{H}_{2} \mathrm{O}_{2}\right)$ formation in an acidified system by oxi-reduction reactions. In these systems, - $\mathrm{OH}$ radicals are formed, which will act on the oxidative degradation of organic pollutants on a Fenton-like reaction $[28,34]$.

The present study's objective was to evaluate the potential of zero-valent copper nanoparticles (nZVC) to degrade the (1-amino-4-[3-(4,6-dichlorotriazin-2-ylamino)-4-sulfophenylamino] anthraquinone-2-sulfonic acid) dye, commercially known as RB4 which is an anthraquinone dye used on the textile sector on dying processes.

\section{Methodology}

2.1. Reagents and Solutions. The chemical reagents, sodium borohydride (Vetec, 98\%), copper sulfate pentahydrate (Vetec, 98\%), and ethanol (Vetec, 95\%), were employed in the nanoparticles synthesis. The Reactive Blue 4 dye (RB4) was purchased from Sigma-Aldrich (35\%, w/w). The sulfuric acid, sodium hydroxide, copper (I) oxide, and tertbutyl alcohol were purchased from Vetec, all in analytical grade. Water purified by the Milli-Q system was used in the preparation of all the solutions used in the experiments. The stock solutions were conditioned under refrigeration at $4^{\circ} \mathrm{C}$.

\subsection{Copper Nanoparticles Preparation and Characterization.} Zero-valent copper nanoparticles (nZVC) were prepared with a minor modification of the method reported by Weng et al. [38] and Shi et al. [39]. The method consists in the chemical reduction of the ions of interest by the reducing agent $\mathrm{NaBH}_{4}$ present in excess. A solution of copper sulfate was prepared by adding $8.8500 \mathrm{~g}$ of copper (II) sulfate pentahydrate over $50 \mathrm{~mL}$ of an ethanol-water $(4: 1, \mathrm{v} / \mathrm{v})$ mixture and stirring for $15 \mathrm{~min}$. A solution of sodium borohydride $\left(1.10 \mathrm{~mol} \mathrm{~L}^{-1}\right)$ was dripped to the mixture at a rate of 1-2 drops per second with constant stirring. The synthesized nanomaterial was vacuum filtered, washed with portions of water and ethanol, and finally dried. The process was concluded by storing the nanoparticles at $-4^{\circ} \mathrm{C}$. The characterization of the nanoparticles was performed using a transmission electron microscope (TEM) (Tecnai G2-20, SuperTwin FEI, Hillsboro, OR, USA).

2.3. RB4 Degradation by $n Z V C$. The reactions were conducted in a cylindrical glass reactor coupled to a digital thermochriostatic bath (Microchemical Mark, Model MQBTC 99-20) for temperature control. The required nZVC mass was added to $200 \mathrm{~mL}$ of aqueous solution containing the RB4 dye under constant temperature and stirring. On certain occasions, the initial $\mathrm{pH}$ of the dye solution $\left(\mathrm{pH}_{0}\right)$ was adjusted to the desired values with diluted solutions of $\mathrm{H}_{2} \mathrm{SO}_{4}$ and $\mathrm{NaOH}$ in the concentration range of 0.01 to $0.5 \mathrm{~mol} \mathrm{~L}{ }^{-1}$. For each time interval, small aliquots $(\approx 2 \mathrm{~mL})$ were collected and filtered on a nitrocellulose membrane $(0.45 \mu \mathrm{m}$ pores $)$ to quantify the dye concentration in solution. Degradation experiments were also performed under oxic conditions (with bubbling of synthetic air) and anoxic conditions (under nitrogen atmosphere) and in the presence of tert-butyl alcohol (TBA) $\left(1 \mathrm{mmol} \mathrm{L}^{-1}\right)$.

2.4. $\mathrm{RB} 4$ Degradation by $\mathrm{Cu}_{2} \mathrm{O}$. The degradation reaction of $200 \mathrm{~mL}$ of a RB4 dye solution in $15 \mathrm{mg} \mathrm{L}^{-1}$ was processed with copper (I) oxide on the relative amount $1.00 \mathrm{~g} \mathrm{~L}^{-1}$ of copper, at $25^{\circ} \mathrm{C}$ without an initial $\mathrm{pH}$ adjustment to the solution.

2.5. Quantification of the RB4 Dye Content in the Samples. The monitoring of RB4 dye degradation was performed using Ultraviolet-Visible (UV-Vis) Absorption Spectrophotometry using a Thermo Scientific (Evolution Array model) spectrophotometer. The monitored wavelength was $599 \mathrm{~nm}$. The concentrations were estimated based on analytical curves, with a linear range of 0 to $60.0 \mathrm{mg} \mathrm{L}^{-1}\left(R^{2}=\right.$ 0.9999).

2.6. Total Organic Carbon (TOC) Analyses. Total Organic Carbon (TOC) analyses were performed using a TOC $5000 \mathrm{~A}$ (Shimadzu, Kyoto, Japan) equipment at $380^{\circ} \mathrm{C}$ utilizing platinum as the catalyst.

2.7. Kinetic Studies. The parameters evaluated in the kinetic studies of the reaction between the RB4 dye and nZVC were as follows: the influence of the nZVC dosage $(0.500$, $1.00,1.50$, and $\left.2.00 \mathrm{~g} \mathrm{~L}^{-1}\right)$; the influence of the $\mathrm{RB} 4$ dye initial concentration, $C_{0}(15.0,25.0,35.0$, and $50.0 \mathrm{mg}$ $\left.\mathrm{L}^{-1}\right)$; the influence of temperature $\left(10,20,25\right.$, and $\left.30^{\circ} \mathrm{C}\right)$; the influence of the solution initial $\mathrm{pH}(3,4,5,7$, and $8)$.

2.8. Copper Nanoparticles Reuse. Experiments involving the reaction between the $\mathrm{RB} 4$ dye and the $\mathrm{nZVC}$ were conducted for $10 \mathrm{~min}$ under the following conditions: $C_{0}=15.0 \mathrm{mg} \mathrm{L}^{-1}$; nZVC dosage $=2.00 \mathrm{~g} \mathrm{~L}^{-1} ; \mathrm{pH}_{0} 3$; and temperature $25^{\circ} \mathrm{C}$. The volume of solution used in the first reaction cycle was $200 \mathrm{~mL}$ and all nanometric material recovered. 


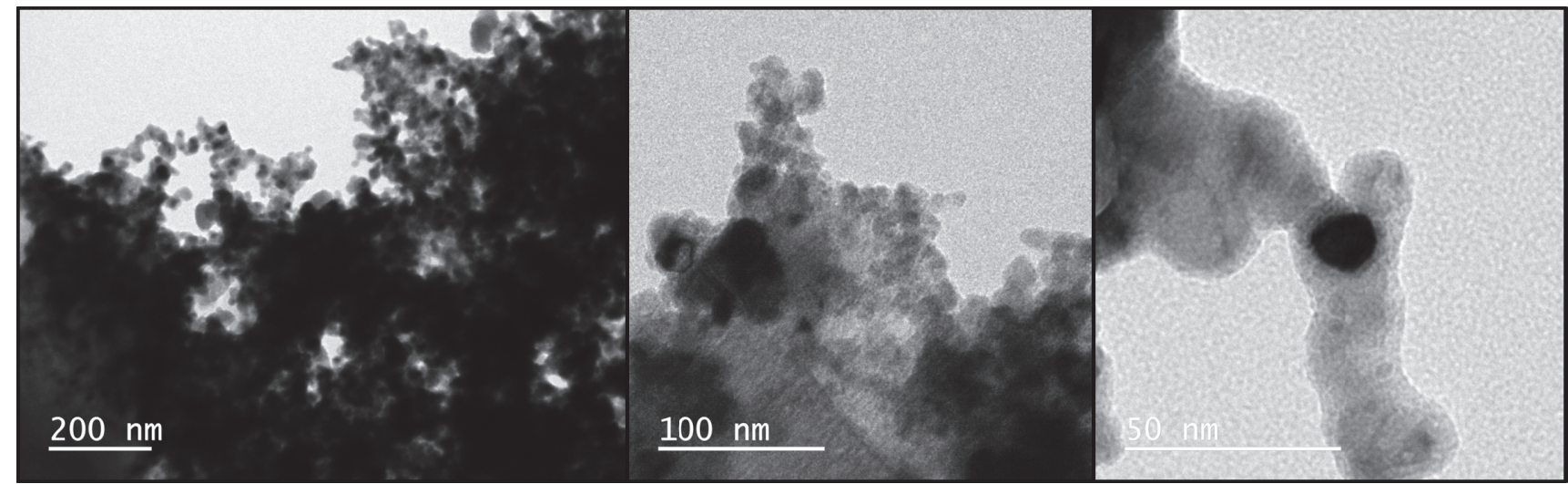

Figure 1: Transmission electron microscope (TEM) images of zero-valent copper nanoparticles in different scales: $200 \mathrm{~nm}$, $100 \mathrm{~nm}$, and $50 \mathrm{~nm}$, respectively.

\section{Results}

3.1. $\mathrm{Cu}{ }^{0}$ Nanoparticles Characterization. The TEM images (Figure 1) show the morphology and structure of the zerovalent copper nanoparticles (nZVC).

It can be observed that the synthesized nanoparticles have spherical structures with randomly arranged heterogeneous diameters. Nanoparticles with sizes in the range of $50 \mathrm{~nm}$ were observed (Figure 1). The small sizes can be associated with an intense homogeneous nucleation kinetics, in which a large number of nucleation sites are formed, mainly due to the molar excess of borohydride added to the copper salt solution, which provides a rapid reduction of the metallic ion; thus, without having time to form nanoparticle clusters, the particles remain in their nanometric size [29]. An agglomeration of the nanoparticles was also found, which is the result of magnetic forces that provoke an attraction between the nanoparticles $[40,41]$. The formed clusters facilitate the handling of the material.

3.2. $R B 4$ Degradation by $n Z V C$. The zero-valent copper nanoparticles efficiency in degrading the Reactive Blue dye 4 (RB4) in an aqueous system was investigated. As shown in Figure 2, there was dye consumption in the reactional system over time, which can be observed by the decay on the absorption bands of 256 and $599 \mathrm{~nm}$ in the ultraviolet-visible region. These bands correspond, respectively, to chlorotriazine and anthraquinone, the main structural groups of the dye $[11,13,19]$. In $15 \mathrm{~min}$, the reaction degradation efficiency reached approximately $90 \%$.

In order to investigate the type of process governing the degradation of RB4 dye by nZVC, TOC (Total Organic Carbon) analyses were performed. There was a $45 \%$ decrease of the TOC value in the system after $15 \mathrm{~min}$ of reaction and the degradation was approximately $70 \%$ (decrease in absorbance). These results indicate the oxidative process as the principal mechanism responsible for the degradation of the RB4 dye by $\mathrm{nZVC}$, since a significant portion of the dye is mineralized. The difference between degradation and mineralization efficiency can be attributed to the processes following different reaction paths, as observed in [19].

Studies were conducted with the scope of verifying the hydroxyl radical $(\bullet \mathrm{OH})$ formation, utilizing tert-butyl alcohol (TBA) as a scavenger of this radical. The TBA is utilized and, thus, enables the identification of Fenton-like systems [28]. The influence of the amount of oxygen present in the system proceeding the reaction under oxic and anoxic conditions was verified during the analysis. There was no significant difference in the degradation process when in the presence or absence of TBA, as well as in the presence or absence of oxygen in the system (Figure 3). Although the reaction of RB4 dye with nZVC occurs in a favorable environment for the formation of $\bullet \mathrm{OH}$ radical, this species is not the main agent responsible for the degradation, concluding this is not a Fenton-like process [28].

As the $\bullet \mathrm{OH}$ radical is not the species governing the oxidative process, it is possible to reason that the $\mathrm{Cu}$ (I) species, formed through the nanoparticles $\mathrm{Cu}^{0}$ oxidation, are in fact acting directly on the dye oxidation. In order to verify this hypothesis, $\mathrm{Cu}_{2} \mathrm{O}$ was utilized as the source of copper (I). The results were compared with those obtained by the reaction utilizing the zero-valence copper nanoparticles, as shown by Figure 4 .

The data demonstrate the $\mathrm{Cu}$ (I) species ability to degrade the RB4 dye, since copper (I) oxide was also able to degrade the dye. According to the literature, $\mathrm{Cu}$ (I) and $\mathrm{Cu}$ (II) ions have redox properties that allow them to easily react with $\mathrm{H}_{2} \mathrm{O}_{2}$ generated in situ, thereby favoring the oxidative process $[28,42]$. However, there are cases where the $\mathrm{Cu}(\mathrm{I})$ is the main constituent responsible for breaking down bonds and generating radicals capable of mineralizing the molecule [34].

It is noteworthy that zero-valent copper nanoparticles are more reactive than copper (I) oxide (Figure 4). In $15 \mathrm{~min}$ of reaction, the degradation rate was $71 \%$ for the reaction utilizing $\mathrm{nZVC}$ and only $5 \%$ for the reaction utilizing $\mathrm{Cu}_{2} \mathrm{O}$. The higher reactivity of the nanoparticles compared to copper (I) oxide is due to the nanoparticles smaller size; as the particles size decreases, the number of atoms located on the surface increases, therefore, allowing the occurrence of 


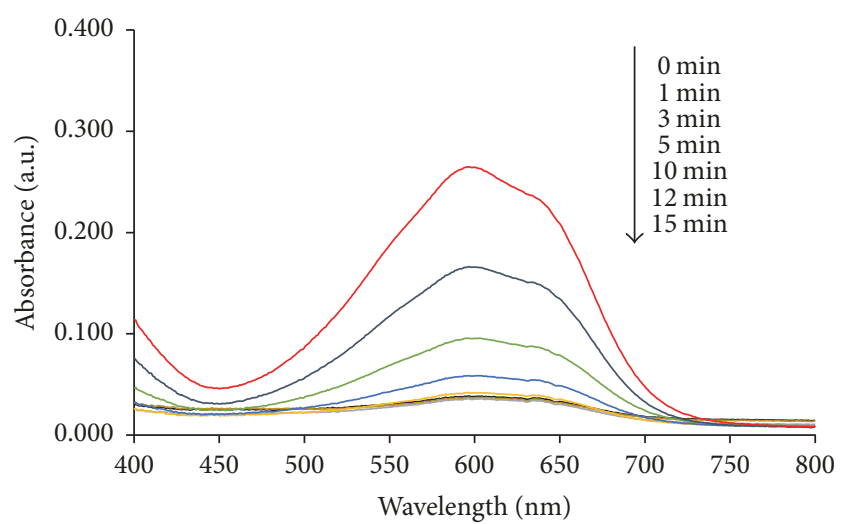

FIGURE 2: UV-Vis spectra of the RB4 dye during the reaction by zerovalent copper nanoparticles. Experimental conditions: $C_{0}=15,0 \mathrm{mg}$ $\mathrm{L}^{-1}$; nZVC dosage $=2,00 \mathrm{~g} \mathrm{~L}^{-1} ; \mathrm{T}=25^{\circ} \mathrm{C}$.

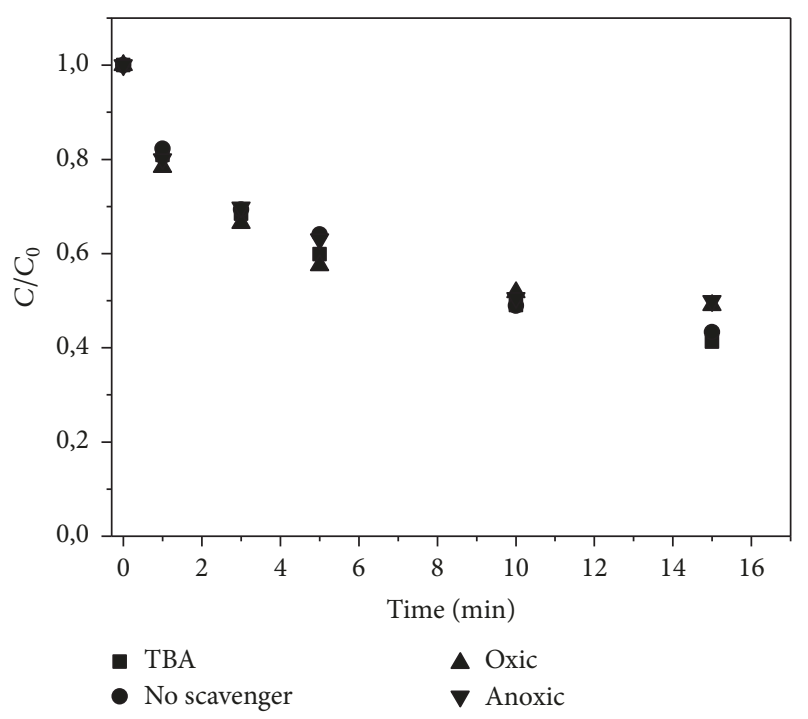

FIGURE 3: Effect of different reaction conditions on the degradation of RB4 dye by zero-valent copper nanoparticles: "⿴囗: presence of TBA (1,0 mmol L $\left.{ }^{-1}\right)$; “๑”: no scavenger (without the presence of TBA); “\$”: under oxic conditions (with bubbling of synthetic air); " $\nabla$ ": under anoxic conditions (nitrogen atmosphere). Experimental conditions: $C_{0}=15,0 \mathrm{mg} \mathrm{L}^{-1} ; \mathrm{nZVC}$ dosage $=1,00 \mathrm{~g} \mathrm{~L}^{-1} ; T=25^{\circ} \mathrm{C}$.

a greater number of chemical events [26]. It is common to verify the decrease or even the absence of reactivity in materials with larger sizes, which makes metallic nanoparticles more efficient on contaminants removal processes $[26,29,43]$.

3.3. RB4 Dye Degradation by $n Z V C$ Kinetics. The degradation reaction kinetics were investigated through the application of linearized equations of first-order (see (1)) and second-order (see (2)) kinetic models [44]. Analyzing Figures 5(a) and 5(b), a good linearity of the data can be observed, in which a better determination coefficient is obtained for the second-order

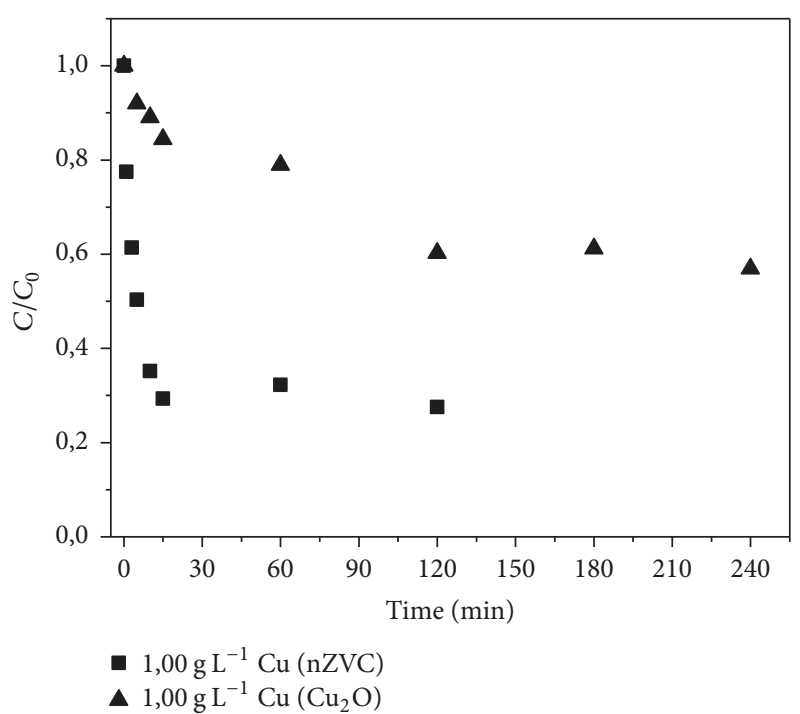

FIGURE 4: Effect of different sources of $\mathrm{Cu}$ (I) on the degradation of RB4 dye: "四": nZVC and "А": cupper (I) oxide. Experimental conditions: $C_{0}=15,0 \mathrm{mg} \mathrm{L}^{-1} ; \mathrm{Cu}$ dosage $=1,00 \mathrm{~g} \mathrm{~L}^{-1} ; T=25^{\circ} \mathrm{C}$.

model $\left(R^{2}=0.9950\right)$ than for the first-order model $\left(R^{2}=\right.$ $0.9353)$.

$$
\begin{gathered}
\ln \left(\frac{C}{C_{0}}\right)=-k_{1} t, \\
\frac{1}{C}-\frac{1}{C_{0}}=k_{2} t .
\end{gathered}
$$

3.3.1. $n Z V C$ Nanoparticle Dosage and Initial Concentration Influence. In one experiment, nZVC doses were used in concentration ranges of $0.500 \mathrm{~g} \mathrm{~L}^{-1}$ to $2.00 \mathrm{~g} \mathrm{~L}^{-1}$. The $\mathrm{nZVC}$ dosage increase favored the dye degradation kinetics. The observed second-order kinetic constants increased with the dosage (Figure 6(a)). On the other hand, the increase on the dye initial concentration resulted in a decrease of the reaction rate constants (Figure 6(b)).

The increased reactions rate with the dose can be explained by the reactive area increase, that is, increase on the copper atoms number at the surface available to react. This behavior has also been observed in other studies, for example, by Bokare et al. [29] and Dutta et al. [35]. That the observed rate constant decreased with the initial concentration increment is unusual, which indicates an inhibition of the reaction with the substrate concentration increase. An explanation for this phenomenon was presented by Liu et al. [25], who suggest a pronounced competitive adsorption of dye molecules on the surface reactive sites, thus diminishing the active surface.

Considering the influence of both nZVC dosage effect and dye initial concentration on the observed kinetic constant, an empirical model was proposed. The model $R^{2}$ is equal to 0.984 and the residuals standard deviation is equal to $2.5 \times 10^{-3} \mathrm{~L} \cdot \mathrm{mg}^{-1} \cdot \mathrm{min}^{-1}$ (Figure 7). 


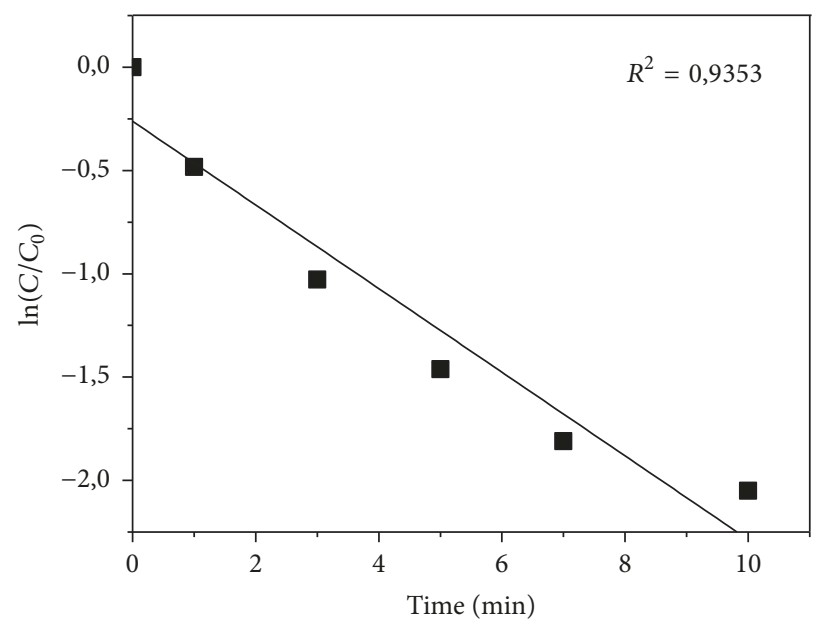

(a)

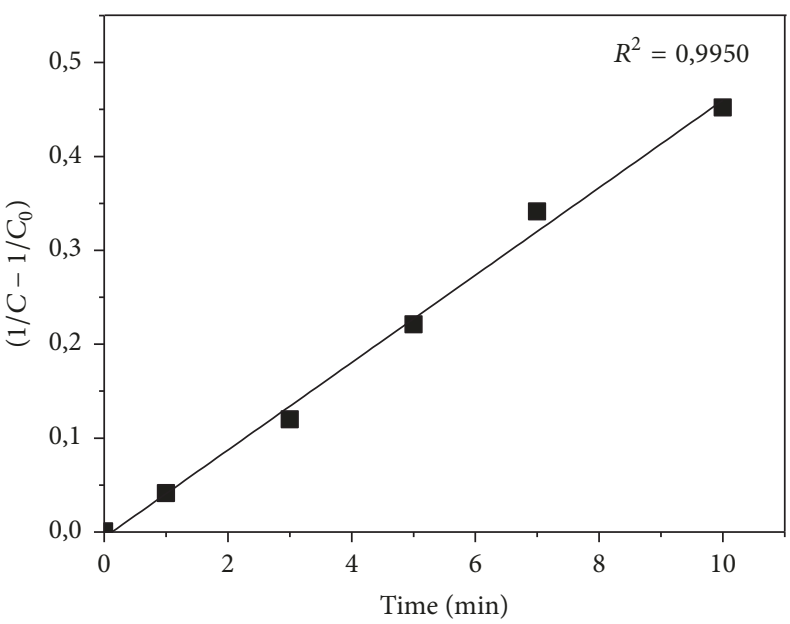

(b)

FIGURE 5: Linear curves of the kinetic models for RB4 degradation by nZVC: (a) first order and (b) second order. Experimental conditions: $C_{0}=15,0 \mathrm{mg} \mathrm{L}^{-1} ; \mathrm{nZVC}$ dosage $=2,00 \mathrm{~g} \mathrm{~L}^{-1} ; T=25^{\circ} \mathrm{C}$.

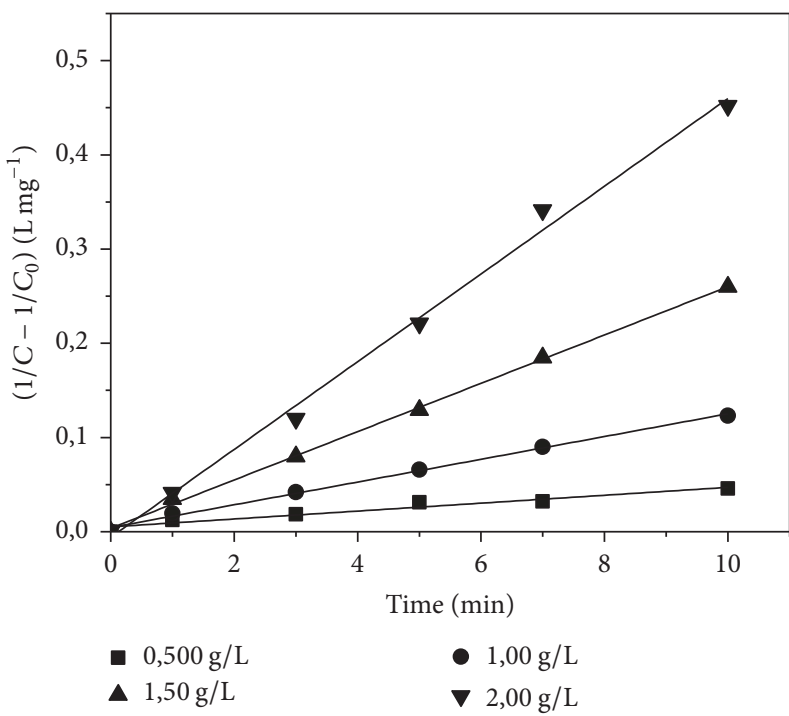

(a)

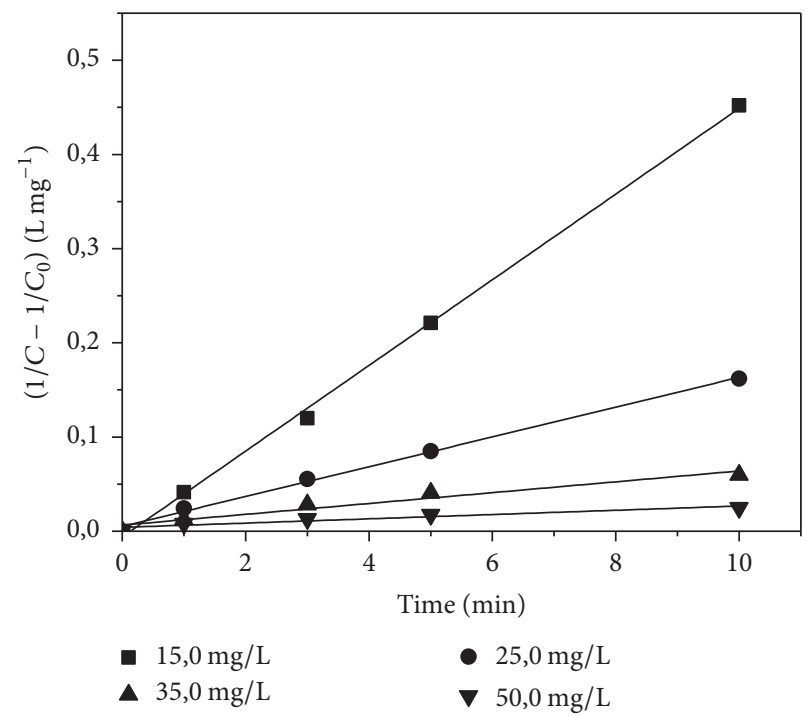

(b)

FIGURE 6: Degradation kinetics effect of RB4 by nZVC: (a) nZVC nanoparticle dosage effect and (b) initial RB4 concentration effect.

3.3.2. Temperature Influence. Analyzing Figure 7(a), the RB4 degradation rate by nZVC tends to increase with an increasing temperature. For systems with temperatures controlled at $10^{\circ} \mathrm{C}, 20^{\circ} \mathrm{C}, 25^{\circ} \mathrm{C}$, and $30^{\circ} \mathrm{C}$, the rate constants were, respectively, $0.005 \mathrm{~L} \mathrm{mg}^{-1} \mathrm{~min}^{-1} ; 0.011 \mathrm{~L} \mathrm{mg}^{-1} \mathrm{~min}^{-1} ; 0.012 \mathrm{~L}$ $\mathrm{mg}^{-1} \mathrm{~min}^{-1}$; and $0.017 \mathrm{~L} \mathrm{mg}^{-1} \mathrm{~min}^{-1}$. After 10 minutes of reaction, the degradation rate already reached $71 \%$ when using a $30^{\circ} \mathrm{C}$ temperature, which was higher than the rates obtained at $25^{\circ} \mathrm{C}(65 \%), 20^{\circ} \mathrm{C}(62 \%)$, and $10^{\circ} \mathrm{C}(3 \%)$ during the same reaction time. Almost $30 \%$ more dye was degraded by raising the temperature from $25^{\circ} \mathrm{C}$ to $30^{\circ} \mathrm{C}$. Endothermic reactions involving metallic nanoparticles have been observed in many studies present on the literature $[41,45,46]$.
The activation energy of RB4 degradation by nZVC was estimated by applying the Arrhenius equation in its linearized form (see (3)), $A$ is the preexponential factor (expressed in the same unit of $k), E_{a}$ is the reaction activation energy $(\mathrm{kJ}$ $\left.\mathrm{mol}^{-1}\right), R$ is the universal gas constant $\left(8.314 \mathrm{~J} \mathrm{~K}^{-1} \mathrm{~mol}^{-1}\right)$, and $T$ is the absolute temperature $(\mathrm{K})$.

$$
\ln k=\ln A-\frac{E_{a}}{R T} .
$$

The value found for $E_{a}$ was $42.41 \mathrm{~kJ} \mathrm{~mol}^{-1}$ (Figure 7(b)); therefore the chemical adsorption at the surface of the nanoparticles governs the degradation rate. This conclusion is in agreement with Zhou et al. [47], who consider degradation 


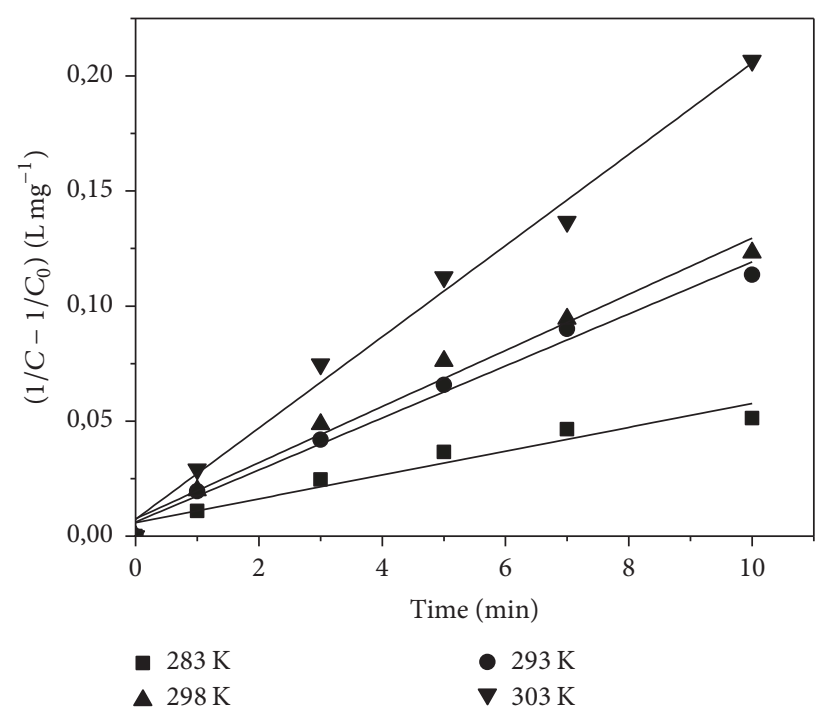

(a)

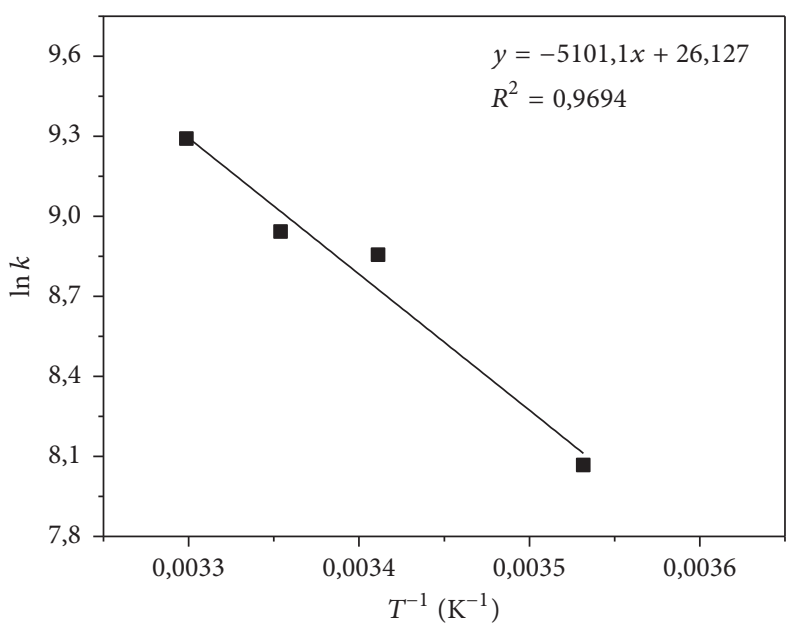

(b)

FIgURE 7: (a) Effect of temperature on the kinetic of RB4 by nZVC and (b) Arrhenius plot for degradation of RB4 by nZVC.

reactions can be kinetically controlled by the mass transfer process (e.g., diffusion of the surface reagent) or by the chemical adsorption on the nanoparticles surface. In the first case, activation energy values were between 8 and $21 \mathrm{~kJ}$ $\mathrm{mol}^{-1}$, while higher values (generally above $29 \mathrm{~kJ} \mathrm{~mol}^{-1}$ ) are indicative of the second process [46-48].

3.3.3. Initial $\mathrm{pH}$ Influence $\left(\mathrm{pH}_{0}\right)$. The effect of the initial $\mathrm{pH}$ $\left(\mathrm{pH}_{0}\right)$ on degradation kinetics was evaluated. During the experiment, the $\mathrm{pH}$ of the dye solution started at 4 and reached values close to 6 at the end of the reaction. The $\mathrm{pH}_{0}$ is an important factor in the kinetics of the dye degradation by nZVC, demonstrated in Figure 8. The observed second-order constants values were $0.021 ; 0.012 ; 0.005 ; 0.003$; and $0.003 \mathrm{~L}$ $\mathrm{mg}^{-1} \min ^{-1}$ when the $\mathrm{pH}_{0}$ was $3,4,5,7$, and 8 , respectively. The degradation efficiency decreased from $71 \%$ to $49 \%, 39 \%$, and $36 \%$ when the $\mathrm{pH}_{0}$ of the dye solution was adjusted to 5,7 , and 8 , respectively, while at $\mathrm{pH}_{0} 3$ the degradation increased to $81 \%$. These results suggest the initial $\mathrm{pH}$ in more acidic conditions is more kinetically favorable for the degradation process of the dye by nZVC.

According to Bokare et al. [29], in aqueous solutions, the nanoparticles surfaces, reagents, and reaction products can present electrical charges. The RB4 dye presents acidbase groups (sulfonic groups and amines), protonated or deprotonated species may exist, and thereby the predominant speciation will depend on the $\mathrm{pH}$ of the system [49]. In the case of metal nanoparticles, they tend to acquire an anionic character in solution, due to the formation of hydroxides on their surface $[35,44]$.

At higher $\mathrm{pH}$ values, the dye negative charges increase combined with the nanoparticles anionic character can promote an electrostatic repulsion and hinder the molecules migration from the solution to the nanoparticles surface [35]. In contrast, lower $\mathrm{pH}$ values accelerate the nZVC oxidation

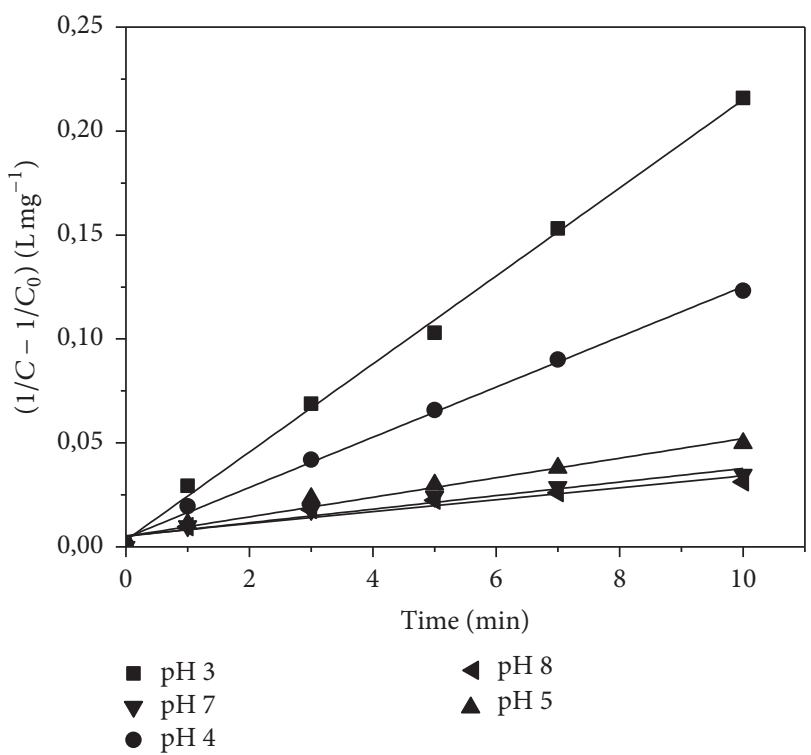

FIGURE 8: Effect of initial $\mathrm{pH}$ on the degradation kinetics of $\mathrm{RB} 4$ by nZVC. Experimental conditions: $C_{0}=15,0 \mathrm{mg} \mathrm{L}^{-1}$; nZVC dosage $=$ $1,00 \mathrm{~g} \mathrm{~L}^{-1} ; T=25^{\circ} \mathrm{C}$.

by dissolving the oxide film which covers the metallic surface [28].

3.4. $\mathrm{Cu}^{0}$ Nanoparticles Reuse. The zero-valence copper nanoparticle reuse studies showed in the first reaction cycle the degradation rate was approximately $90 \%$, while in the second cycle the nZVC degraded at a lower rate (73\%) considering the same reaction time. Evaluating the kinetic aspects, there was a loss of the nanoparticle catalytic activity with its use. The value of second-order constants observed 
$0.053 \mathrm{~L} \mathrm{mg}^{-1} \mathrm{~min}^{-1}$ for the first cycle and $0.018 \mathrm{~L} \mathrm{mg}^{-1} \mathrm{~min}^{-1}$ for the second cycle. This decrease in rate constant may be due to metal surface oxidation or metal hydroxide/oxide deposition, which decreases the number of nanoparticles adsorptive and reactive sites [25]. According to Raut et al. [32], these reuse studies are crucial to evaluate the catalytic effect repeatability and the degradation method savings.

\section{Conclusion}

The use of zero-valence copper nanoparticles was shown to be promising for the Reactive Blue 4 dye degradation, obtaining rates close to $90 \%$ in a short reaction time. It was observed that the dye initial concentration is a limitation, which causes the decrease of the degradation rate. Formulating the initial $\mathrm{pH}$ of the solution slightly more acidic favored the degradation kinetics. The temperature increase accelerates the reaction because the degradation reaction is an endothermic process. The nanoparticles dosage also influenced the reaction kinetics; thus a higher degradation rate was reached when the system started to have more reactive and adsorptive sites and greater specific area. The TOC analysis suggests the oxidative process might be the predominant mechanism, considering the mineralization of a large portion in the sample. The $\bullet \mathrm{OH}$ radicals influence was not observed, in contrast to the monovalent copper action, which leads the data to suggest $\mathrm{Cu}$ (I) species are the main contributing factor for the degradation process. The estimated activation energy $\left(E_{a}\right)$ was about $42 \mathrm{~kJ} \mathrm{~mol}^{-1}$ and the kinetic model that best described the experimental behavior was the second-order model. In the process of the nanoparticles reuse, a small loss of catalytic activity was observed, but, even so, a good degradation rate $(73 \%)$ was obtained in the second cycle of the nanomaterial use.

\section{Conflicts of Interest}

The authors declare that they have no conflicts of interest regarding the publication of this paper.

\section{Acknowledgments}

The authors thank the financial support from $\mathrm{CNPq} /$ FAPEMIG (agreement recorded in SICONV: 793988/2013), FAPEMIG, CAPES, and CNPq (National Council for Scientific and Technology Development-449909/2014-0 process). They thank Stephanie L. Ray, M.S. in geology, for the comments that greatly improved the manuscript. The authors also acknowledge the Microscopy Center at the Federal University of Minas Gerais (http://www.microscopia.ufmg.br) for providing the equipment and technical support for the experiments involving electron microscopy.

\section{References}

[1] ABIT (Associação Brasileira da Indústria Têxtil e de Confecção), "Indústria têxtil e de confecção brasileira: cenários, desafios, perspectivas e demandas," 2016, http://www.abit.org .br/conteudo/links/publicacoes/cartilha_rtcc.pdf.
[2] ABDI (Agência Brasileira de Desenvolvimento da Indústria), "Relatório de acompanhamento setorial - têxtil e confecção," 2016, http://www.abdi.com.br/Estudo/textil\%20e\%20confeccao\%20junho\%2008.pdf.

[3] D. K. Gardiner and B. J. Borne, "Textile waste waters: treatment and environmental effects," Journal of the Society of Dyers and Colourists, vol. 94, no. 8, pp. 339-348, 1978.

[4] C. C. Guaratini and M. V. Zanoni, "Corantes têxteis," Química Nova, vol. 23, no. 1, pp. 71-78, 2000.

[5] L. E. Sendelbach, "A review of the toxicity and carcinogenicity of anthraquinone derivatives," Toxicology, vol. 57, no. 3, pp. 227240, 1989.

[6] F. A. Esteve-Turrillas and M. de la Guardia, "Environmental impact of recover cotton in textile industry," Resources, Conservation \& Recycling, vol. 116, pp. 107-115, 2017.

[7] H. Karaer and I. Kaya, "Synthesis, characterization of magnetic chitosan/active charcoal composite and using at the adsorption of methylene blue and reactive blue4," Microporous and Mesoporous Materials, vol. 232, pp. 26-38, 2016.

[8] M. Vakili, M. Rafatullah, M. H. Ibrahim, A. Z. Abdullah, Z. Gholami, and B. Salamatinia, "Enhancing reactive blue 4 adsorption through chemical modification of chitosan with hexadecylamine and 3-aminopropyl triethoxysilane," Journal of Water Process Engineering, vol. 15, pp. 49-54, 2017.

[9] O. Tkachenko, A. Panteleimonov, I. Padalko, A. Korobov, Y. Gushikem, and Y. Kholin, "Silica functionalized with 1-propyl3-methylimidazolium chloride as an efficient adsorbent for the removal of Eosin Yellow and Reactive Blue 4," Chemical Engineering Journal, vol. 254, pp. 324-332, 2014.

[10] V. Dhanapal and K. Subramanian, "Modified chitosan for the collection of reactive blue 4 , arsenic and mercury from aqueous media," Carbohydrate Polymers, vol. 117, pp. 123-132, 2015.

[11] N. R. Neti and R. Misra, "Efficient degradation of reactive blue 4 in carbon bed electrochemical reactor," Chemical Engineering Journal, vol. 184, pp. 23-32, 2012.

[12] B. Gözmen, B. Kayan, A. M. Gizir, and A. Hesenov, "Oxidative degradations of reactive blue 4 dye by different advanced oxidation methods," Journal of Hazardous Materials, vol. 168, no. 1, pp. 129-136, 2009.

[13] P. A. Carneiro, M. E. Osugi, C. S. Fugivara, N. Boralle, M. Furlan, and M. V. B. Zanoni, "Evaluation of different electrochemical methods on the oxidation and degradation of Reactive Blue 4 in aqueous solution," Chemosphere, vol. 59, no. 3, pp. 431439, 2005.

[14] J. M. Monteagudo, A. Durán, I. S. Martín, and S. García, "Ultrasound-assisted homogeneous photocatalytic degradation of reactive blue 4 in aqueous solution," Applied Catalysis B: Environmental, vol. 152-153, pp. 59-67, 2014.

[15] J. M. Monteagudo, A. Durán, M. Aguirre, and I. S. Martín, "Photodegradation of reactive blue 4 solutions under ferrioxalateassisted UV/solar photo-fenton system with continuous addition of $\mathrm{H}_{2} \mathrm{O}_{2}$ and air injection," Chemical Engineering Journal, vol. 162, no. 2, pp. 702-709, 2010.

[16] A. Durán, J. M. Monteagudo, and E. Amores, "Solar photofenton degradation of reactive blue 4 in a CPC reactor," Applied Catalysis B: Environmental, vol. 80, no. 1-2, pp. 42-50, 2008.

[17] A. Durán and J. M. Monteagudo, "Solar photocatalytic degradation of reactive blue 4 using a Fresnel lens," Water Research, vol. 41, no. 3, pp. 690-698, 2007.

[18] P. A. Carneiro, R. F. P. Nogueira, and M. V. B. Zanoni, "Homogeneous photodegradation of C.I. Reactive Blue 4 using 
a photo-Fenton process under artificial and solar irradiation," Dyes and Pigments, vol. 74, no. 1, pp. 127-132, 2007.

[19] O. B. Ayodele and O. S. Togunwa, "Catalytic activity of copper modified bentonite supported ferrioxalate on the aqueous degradation and kinetics of mineralization of Direct Blue 71, Acid Green 25 and Reactive Blue 4 in photo-Fenton process," Applied Catalysis A: General, vol. 470, pp. 285-293, 2014.

[20] J. Axelsson, U. Nilsson, E. Terrazas, T. Alvarez Aliaga, and U. Welander, "Decolorization of the textile dyes reactive red 2 and reactive blue for using Bjerekandera sp. strain Bol 13 in a continuous rotating biological contactor reactor," Enzyme and Microbial Technology, vol. 39, no. 1, pp. 32-37, 2006.

[21] G. Bayramoğlu, G. Çelik, and M. Y. Arica, "biosorption of reactive blue 4 dye by native and treated fungus Phanerocheate chrysosporium: batch and continuous flow system studies," Journal of Hazardous Materials, vol. 137, no. 3, pp. 1689-1697, 2006.

[22] A. R. Binupriya, M. Sathishkumar, C. S. Ku, and S.-I. Yun, "Sequestration of reactive blue 4 by free and immobilized bacillus subtilis cells and its extracellular polysaccharides," Colloids and Surfaces B: Biointerfaces, vol. 76, no. 1, pp. 179-185, 2010.

[23] W. S. Pereira and R. S. Freire, "Ferro zero: uma nova abordagem para o tratamento de águas contaminadas com compostos orgânicos poluentes," Química Nova, vol. 28, no. 1, pp. 130-136, 2005.

[24] C. D. Raman and S. Kanmani, "Textile dye degradation using nano zero valent iron: a review," Journal of Environmental Management, vol. 177, pp. 341-355, 2016.

[25] W.-J. Liu, T.-T. Qian, and H. Jiang, "Bimetallic Fe nanoparticles: recent advances in synthesis and application in catalytic elimination of environmental pollutants," Chemical Engineering Journal, vol. 236, pp. 448-463, 2014.

[26] D. O'Carroll, B. Sleep, M. Krol, H. Boparai, and C. Kocur, "Nanoscale zero valent iron and bimetallic particles for contaminated site remediation," Advances in Water Resources, vol. 51, no. 1, pp. 104-122, 2013.

[27] R. A. Crane and T. B. Scott, "Nanoscale zero-valent iron: future prospects for an emerging water treatment technology," Journal of Hazardous Materials, vol. 211-212, pp. 112-125, 2012.

[28] G. Wen, S.-J. Wang, J. Ma et al., "Oxidative degradation of organic pollutants in aqueous solution using zero valent copper under aerobic atmosphere condition," Journal of Hazardous Materials, vol. 275, pp. 193-199, 2014.

[29] A. D. Bokare, R. C. Chikate, C. V. Rode, and K. M. Paknikar, "Iron-nickel bimetallic nanoparticles for reductive degradation of azo dye Orange $\mathrm{G}$ in aqueous solution," Applied Catalysis B: Environmental, vol. 79, no. 3, pp. 270-278, 2008.

[30] C. J. Lin, S.-L. Lo, and Y. H. Liou, "Degradation of aqueous carbon tetrachloride by nanoscale zerovalent copper on a cation resin," Chemosphere, vol. 59, no. 9, pp. 1299-1307, 2005.

[31] C.-C. Huang, S.-L. Lo, and H.-L. Lien, "Zero-valent copper nanoparticles for effective dechlorination of dichloromethane using sodium borohydride as a reductant," Chemical Engineering Journal, vol. 203, pp. 95-100, 2012.

[32] S. S. Raut, S. P. Kamble, and P. S. Kulkarni, "Efficacy of zerovalent copper $\left(\mathrm{Cu}_{0}\right)$ nanoparticles and reducing agents for dechlorination of mono chloroaromatics," Chemosphere, vol. 159, pp. 359-366, 2016.

[33] P. Li, Y. Song, S. Wang, Z. Tao, S. Yu, and Y. Liu, "Enhanced decolorization of methyl orange using zero-valent copper nanoparticles under assistance of hydrodynamic cavitation," Ultrasonics Sonochemistry, vol. 22, pp. 132-138, 2015.

[34] G. Dong, Z. Ai, and L. Zhang, "Total aerobic destruction of azo contaminants with nanoscale zero-valent copper at neutral $\mathrm{pH}$ : Promotion effect of in-situ generated carbon center radicals," Water Research, vol. 66, pp. 22-30, 2014.

[35] S. Dutta, R. Saha, H. Kalita, and A. N. Bezbaruah, "Rapid reductive degradation of azo and anthraquinone dyes by nanoscale zero-valent iron," Environmental Technology and Innovation, vol. 5, pp. 176-187, 2016.

[36] Y. He, J.-F. Gao, F.-Q. Feng, C. Liu, Y.-Z. Peng, and S.-Y. Wang, "The comparative study on the rapid decolorization of azo, anthraquinone and triphenylmethane dyes by zero-valent iron," Chemical Engineering Journal, vol. 179, pp. 8-18, 2012.

[37] A. D. Bokare, R. C. Chikate, C. V. Rode, and K. M. Paknikar, "Effect of surface chemistry of Fe-Ni nanoparticles on mechanistic pathways of azo dye degradation," Environmental Science \& Technology, vol. 41, no. 21, pp. 7437-7443, 2007.

[38] X. Weng, Q. Sun, S. Lin, Z. Chen, M. Megharaj, and R. Naidu, "Enhancement of catalytic degradation of amoxicillin in aqueous solution using clay supported bimetallic $\mathrm{Fe} / \mathrm{Ni}$ nanoparticles," Chemosphere, vol. 103, pp. 80-85, 2014.

[39] L.-N. Shi, X. Zhang, and Z.-L. Chen, "Removal of chromium (VI) from wastewater using bentonite-supported nanoscale zero-valent iron: kinetics, $\mathrm{pH}$ effect, and degradation mechanism," Water Research, vol. 45, no. 2, pp. 886-892, 2011.

[40] Z. Fang, X. Qiu, J. Chen, and X. Qiu, "Debromination of polybrominated diphenyl ethers by Ni/Fe bimetallic nanoparticles: Influencing factors, kinetics, and mechanism," Journal of Hazardous Materials, vol. 185, no. 2-3, pp. 958-969, 2011.

[41] Y.-H. Shih, C.-Y. Hsu, and Y.-F. Su, "Pentachlorophenol reduction by Pd/Fe bimetallic nanoparticles: effects of copper, nickel, and ferric cations," Applied Catalysis B: Environmental, vol. 76, pp. 286-274, 2011.

[42] A. D. Bokare and W. Choi, "Review of iron-free Fenton-like systems for activating $\mathrm{H} 2 \mathrm{O} 2$ in advanced oxidation processes," Journal of Hazardous Materials, vol. 275, pp. 121-135, 2014.

[43] B. Schrick, J. L. Blough, A. D. Jones, and T. E. Mallouk, "Hydrodechlorination of trichloroethylene to hydrocarbons using bimetallic nickel-iron nanoparticles," Chemistry of Materials, vol. 14, no. 12, pp. 5140-5147, 2002.

[44] M. A. Mekewi, A. S. Darwish, M. S. Amin, G. Eshaq, and H. A. Bourazan, "Copper nanoparticles supported onto montmorillonite clays as efficient catalyst for methylene blue dye degradation," Egyptian Journal of Petroleum, vol. 25, no. 2, pp. 269-279, 2016.

[45] W. J. Epolito, H. Yang, L. A. Bottomley, and S. G. Pavlostathis, "Kinetics of zero-valent iron reductive transformation of the anthraquinone dye Reactive Blue 4," Journal of Hazardous Materials, vol. 160, no. 2-3, pp. 594-600, 2008.

[46] F. Wang, Y. Gao, Q. Sun, Z. Chen, M. Megharaj, and R. Naidu, "Degradation of microcystin-LR using functional clay supported bimetallic Fe/Pd nanoparticles based on adsorption and reduction," Chemical Engineering Journal, vol. 255, pp. 5562, 2014.

[47] T. Zhou, Y. Li, and T.-T. Lim, "Catalytic hydrodechlorination of chlorophenols by Pd/Fe nanoparticles: Comparisons with other bimetallic systems, kinetics and mechanism," Separation and Purification Technology, vol. 76, no. 2, pp. 206-214, 2010.

[48] X. Weng, S. Lin, Y. Zhong, and Z. Chen, "Chitosan stabilized bimetallic $\mathrm{Fe} / \mathrm{Ni}$ nanoparticles used to remove mixed 
contaminants-amoxicillin and Cd (II) from aqueous solutions," Chemical Engineering Journal, vol. 229, pp. 27-34, 2013.

[49] W. J. Epolito, Y. H. Lee, L. A. Bottomley, and S. G. Pavlostathis, "Characterization of the textile anthraquinone dye Reactive Blue 4," Dyes and Pigments, vol. 67, no. 1, pp. 35-46, 2005. 


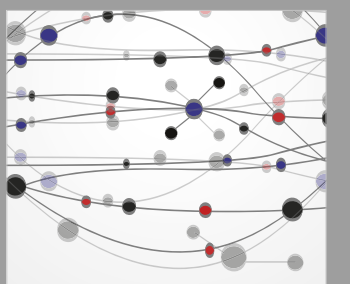

The Scientific World Journal
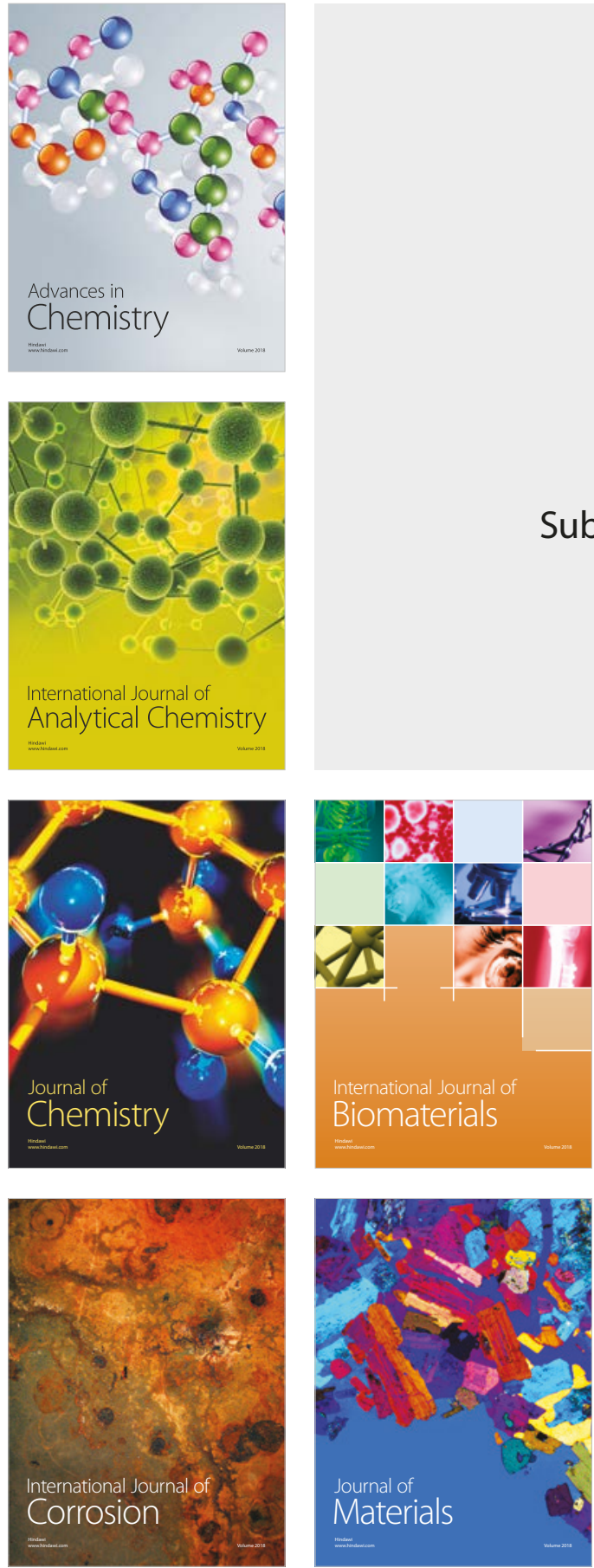

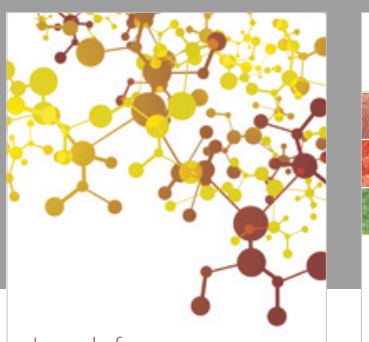

Journal of

Applied Chemistry
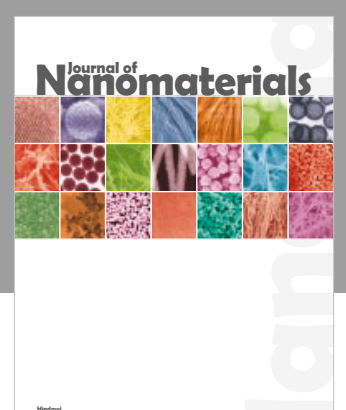

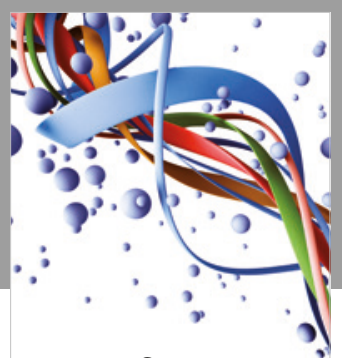

Scientifica

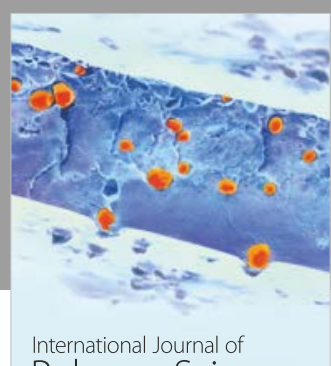

Polymer Science

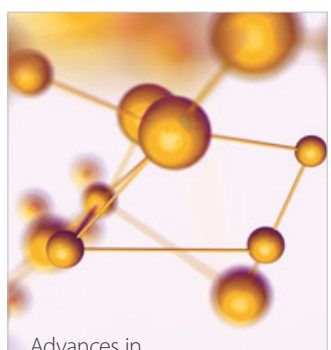

Physical Chemistry
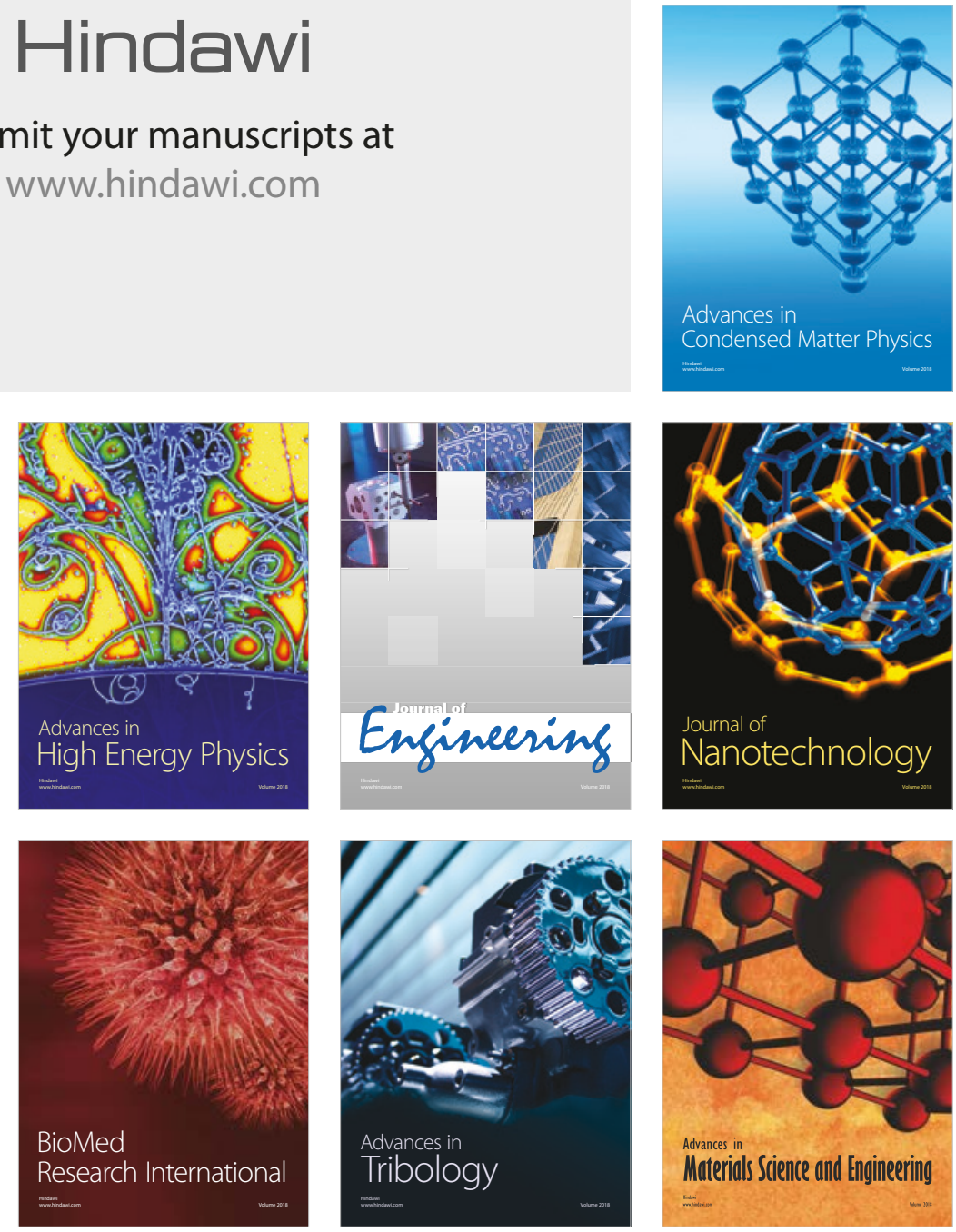